\title{
Minimizing Base Loss and Internal Fragmentation in Collisionally Activated Dissociation of Multiply Deprotonated RNA
}

\author{
Monika Taucher, Ulrike Rieder, and Kathrin Breuker \\ Institute of Organic Chemistry and Center for Molecular Biosciences (CMBI), University of Innsbruck, \\ Innsbruck, Austria
}

In recent years, new classes of nonprotein-coding ribonucleic acids (ncRNAs) with important cellular functions have been discovered. Of particular interest for biomolecular research and pharmaceutical developments are small ncRNAs that are involved in gene regulation, such as small interfering RNAs (21-28 nt), pre-microRNAs (70-80 nt), or riboswitches (34-200 nt). De novo sequencing of RNA by top-down mass spectrometry has so far been limited to RNA consisting of up to $\sim 20 \mathrm{nt}$. We report here complete sequence coverage for $34 \mathrm{nt}$ RNA (10.9 kDa), along with 30 out of 32 possible complementary ion pairs from collisionally activated dissociation (CAD) experiments. The key to minimizing undesired base loss and internal fragmentation is to minimize the internal energy of fragment ions from primary backbone cleavage. This can be achieved by collisional cooling of primary fragment ions and selection of precursor ions of relatively low negative net charge (about -0.2/nt). (J Am Soc Mass Spectrom 2010, 21, 278-285) (C) 2010 American Society for Mass Spectrometry

$\mathrm{I}$ their 1995 review on the characterization of oligonucleotides and nucleic acids by mass spectrometry [1], Limbach et al. remark that "One of the most promising methods for sequencing oligonucleotides below the $\sim 25$-mer level involves the mass analysis of fragment ions resulting from backbone cleavage, which are then used to construct a 'mass ladder' ... Although optimism is warranted for the achievement of direct sequencing of oligonucleotides by mass spectrometry within the next year or so, it has not yet been demonstrated that complete sequences of structurally unknown oligonucleotides can be routinely determined." Today, in 2009, 'direct sequencing' by MS is still restricted to smaller oligonucleotides, with limits of $\sim 25$ nt for DNA [2] and $\sim 20 \mathrm{nt}$ for RNA [3]. Recent studies are mostly focused on the use of chemical [4] and enzymatic $[5,6]$ digestion, similar to the 'bottom-up' methodology used for protein identification [7]. However, the alternative 'top-down' [8,9] approach offers unique advantages over the 'bottom-up' strategy, such as immediate information about sample heterogeneity, and potentially a complete description of primary structure, including modifications [10]. Limiting factors for de novo sequencing by top-down MS of oligonucleotides using collisionally activated dissociation (CAD) are base loss, secondary backbone dissociation, and multiple backbone fragmentation channels (Scheme 1). McLuckey and coworkers recently demonstrated com-

Address reprint requests to Dr. K. Breuker, Institute of Organic Chemistry and Center for Molecular Biosciences (CMBI), University of Innsbruck, Innrain 52a, A-6020 Innsbruck, Austria. E-mail: kathrin.breuker@uibk.ac.at plete sequence information for $21 \mathrm{nt}$ siRNA, using precursor ions of relatively low charge in ion trap CAD at relatively low excitation energy [3]. Their CAD spectrum of $(\mathrm{M}-5 \mathrm{H})^{5-}$ ions of $21 \mathrm{nt}$ siRNA was dominated by $c$ - and $y$-type fragment ions (Scheme 1 ) that include either the $5^{\prime}$ - or $3^{\prime}$-terminus ("terminal fragments," as opposed to "internal fragments" from secondary backbone dissociation).

Collisionally activated dissociation of $(\mathrm{M}-\mathrm{H})^{-}$ions of RNA dinucleotides in a linear quadrupole ion trap produced $(\mathrm{M}-\mathrm{H}-\mathrm{B})^{-}$and $(\mathrm{B}-\mathrm{H})^{-}$ions from loss of neutral and charged base $B$, respectively, as well as $w$-, $x-, c-$, and $d$-type fragment ions from RNA backbone cleavage (Scheme 1) [11, 12]. Among all dissociation channels, loss of the $5^{\prime}$ base and backbone cleavage yielding $c / y$ products were the most favored, and also showed the lowest excitation amplitude thresholds [12]. Likewise, beam-type CAD of $(\mathrm{M}-2 \mathrm{H})^{2-}$ ions of $4 \mathrm{nt}$ RNA (UAUU) gave $(\mathrm{M}-2 \mathrm{H}-\mathrm{U})^{2-}$ and products from all four backbone dissociation channels $(a / w, b / x, c / y$, and $d / z$ ), with preference for $c / y$ cleavage [13]. Schürch and coworkers presented evidence that $c / y$ cleavage involves the 2'-OH group of the ribose, and that nucleobase loss is an independent dissociation channel [1315]. Backbone dissociation of somewhat larger RNA apparently strongly favors the $a / w$ and $c / y$ over $b / x$ and $d / z$ channels: Schürch and coworkers observed only $\sim 2 \% b / x$ and $d / z$ products in beam-type CAD of $(\mathrm{M}-$ $3 \mathrm{H})^{3-}$ and $(\mathrm{M}-4 \mathrm{H})^{4-}$ ions of 12 and 14 nt RNA, respectively, compared with $\sim 28 \%$ a/w (including abundant $a$-B ions) and $\sim 70 \% c / y$ products [15]. McLuckey and coworkers reported that the backbone 


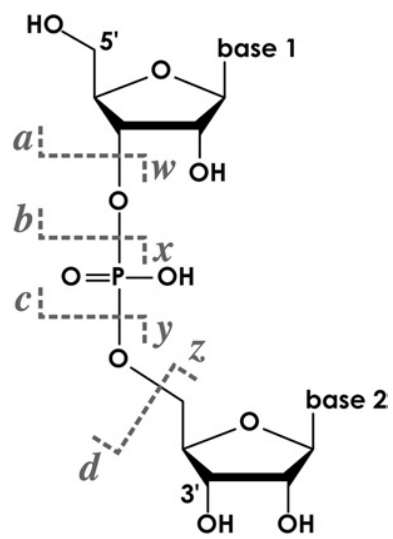

Scheme 1. RNA fragment ion nomenclature according to McLuckey, Van Berkel, and Glish [11].

dissociation products in both beam-type and ion trap CAD of $(\mathrm{M}-5 \mathrm{H})^{5-}$ ions of $21 \mathrm{nt}$ single strands of siRNA were from the $a / w$ (including $a$-B ions) and $c / y$ channels, with the latter dominating at lower excitation energies [3]. Products from other backbone cleavages were observed at relatively low abundance when relatively high excitation amplitudes were used in ion trap CAD [3]. In a comprehensive study on the effect of anion charge state on branching ratio between a/w (including $\boldsymbol{a}$-B ions) and $c / y$ channels using $8 \mathrm{nt}$ RNA (GCGGAUUU), McLuckey and coworkers showed that CAD of $(\mathrm{M}-2 \mathrm{H})^{2-}$ to $(\mathrm{M}-5 \mathrm{H})^{5-}$ ions gave $\sim 60 \%$ and $\sim 50 \% c / y$ ions at low and high excitation amplitudes, respectively [12]. In contrast, CAD of the $(\mathrm{M}-6 \mathrm{H})^{6-}$ ions gave $0 \%$ and $\sim 10 \%$ cly products at low and high excitation amplitudes, respectively, with charged base loss as the only product at low excitation amplitude [12]. From the above data, apparently the most crucial factors determining the branching ratio between $a / w$, $b / x, c / y, d / z$, and base loss channels in CAD of smaller (up to $\sim 20 \mathrm{nt}$ ) RNA anions $(\mathrm{M}-\mathrm{nH})^{\mathrm{n}-}$ are excitation energy, ion charge state $n$, and oligomer length.

We present here a systematic study on CAD of somewhat larger RNA (34 nt), under the aspects of branching ratio between backbone dissociation and base loss channels as well as secondary backbone dissociation. We demonstrate that undesired base loss and secondary fragmentation can be reduced by collisional cooling of primary backbone fragments. Moreover, we show that CAD of $34 \mathrm{nt}$ RNA precursor ions carrying about -0.2 charges per nucleotide strongly favors backbone dissociation via the $c / y$ channel $(>90 \%$ of all terminal fragments), producing relatively simple spectra that can be used for de novo sequencing.

\section{Experimental}

RNA was prepared using a solid-phase synthesis approach described recently [16, 17], followed by HPLC purification and desalting using vivaspin 500 centrifugal concentrators (Sartorius, Göttingen, Germany, PES membrane, MWCO 3000). For desalting, $500 \mu \mathrm{L}$ of aqueous RNA solution $(10 \mu \mathrm{M})$ was concentrated to 100 $\mu \mathrm{L}$, and $400 \mu \mathrm{L}$ of $100 \mathrm{mM}$ ammonium acetate in $\mathrm{H}_{2} \mathrm{O}$ (18 $\mathrm{M} \Omega$ ) was added. The process was repeated three times, followed by seven cycles of concentration and dilution with $\mathrm{H}_{2} \mathrm{O}(18 \mathrm{M} \Omega)$. The $34 \mathrm{nt}$ riboswitch aptamer domain sequence [17] was AGUCG UGCUA GCAAA ACCGG CUUUA AAAAA CUAG, with hydroxyl groups at the $3^{\prime}$ and $5^{\prime}$ termini. Variant $C$ carried $\mathrm{OCH}_{3}$ groups at the ribose $\mathrm{C}^{\prime}$-positions of $\mathrm{C} 4$ and $\mathrm{G} 20$, and variant $\mathrm{B}$ carried $\mathrm{OCH}_{3}$ groups at the ribose $\mathrm{C2}^{\prime}$ positions of $\mathrm{C} 4$ and $\mathrm{A} 30$. The effect of $\mathrm{OCH}_{3}$ modifications on dissociation will be addressed in detail in a separate publication. Final RNA concentration in the ESI solution (50:50 or 70:30 $\left.\mathrm{H}_{2} \mathrm{O} / \mathrm{MeOH}\right)$ was $1 \mu \mathrm{M}$, with the $\mathrm{pH}$ adjusted to 9.5 or 2.5 by addition of triethylamine $\left(\mathrm{Et}_{3} \mathrm{~N}, \sim 1 \%\right.$ vol.) or acetic acid (HOAc, $\sim 0.05 \%$ vol.), respectively. Because of clogging problems with nano-ESI emitters, we used micro-ESI at 1.5-2.0 $\mu \mathrm{L} / \mathrm{min}$ flow rate. All solvents used were HPLC grade. Ammonium acetate (puriss p.a., $\geq 99.0 \%$ ), triethylamine (puriss p.a., $\geq 99.5 \%$ ), and acetic acid (puriss p.a., $\geq 99.8 \%$ ) were from Sigma-Aldrich, Vienna, Austria.

MS and MS/MS experiments were performed on a 7 Tesla Fourier transform-ion cyclotron resonance (FTICR) mass spectrometer equipped with an electrospray ionization (ESI) source (apex ultra 70; Bruker Austria $\mathrm{GmbH}$, Vienna, Austria). RNA dissociation was effected by collisionally activated dissociation in a linear hexapole ion trap (H2) floated with Argon as collision gas (Scheme 2). Laboratory frame collision energy is defined here as the bias potential difference between the second ion funnel (F2) and the collision cell's hexapole $(\mathrm{H} 2) \times$ the ion's charge. With this experimental setup, ions are accelerated from the lower pressure $\mathrm{H} 1$ and $\mathrm{Q}$ regions into the collision cell (H2). Because we cannot exclude that some deactivating and/or activating ion-neutral collisions occur in the lower pressure $\mathrm{H} 1$ and $\mathrm{Q}$ regions, laboratory frame collision energies are not absolute but rather taken as a relative measure of the energy available for dissociation. After selection of ions of a given $m / z$ in the linear quadrupole (Q), ions enter the collision cell, where they collide with Argon gas. The selected ions are actually accelerated into a pressure gradient, with longer mean free paths on the lower pressure side (towards Q) effecting higher-energy (activating) ion-neutral collisions, and shorter mean

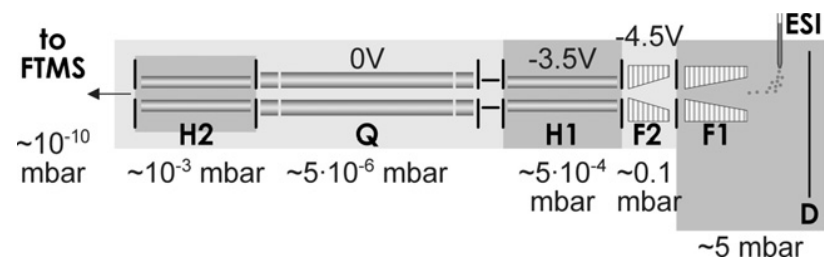

Scheme 2. Experimental setup for CAD experiments. Ions travel from right to left. D: ion deflector; F1, F2: ion funnels; H1: accumulation hexapole; Q: quadrupole for ion selection; H2: linear hexapole ion trap in collision cell. 
free paths in the higher pressure region near the center of the collision cell resulting in numerous lower-energy (deactivating) collisions. Increasing the collision gas flow rate results in an increased local Argon pressure near the center of the collision cell and a steeper pressure gradient along the ion flight path. CAD products were accumulated in the collision cell for $1 \mathrm{~s}$, followed by transfer into the FT-ICR cell for detection. For increased statistics, each mass spectrum is an average of 500 scans. Reproducibility of spectra recorded on our instrument under the same experimental condition was very high, which is also evident from the relatively small scatter of the data collected over a period of several months. However, the internal energy of precursor ions before collisional activation can differ for different ESI sources [18] and ion transfer designs. Moreover, the exact amount of energy imparted into the precursor ions during low-energy collisional activation cannot be determined accurately for many instrumental setups, including ours. Therefore, the total energy available for dissociation (internal energy before activation plus the energy added during activation) is more or less unknown, and data obtained on different instruments may not be directly comparable. A possible way of standardizing the spectra is to consider the extent of molecular ion dissociation; such values are included in this study.

For data reduction, the SNAP2 algorithm (Bruker Daltonics, Bremen, Germany) adapted here for analysis of RNA was used. We defined an RNA building block for calculation of isotopic profiles with elemental composition $\mathrm{C}_{9.5} \mathrm{~N}_{3.75} \mathrm{O}_{7} \mathrm{P}_{1} \mathrm{H}_{11.75}$, which is the averaged elemental composition of $\mathrm{A}\left(\mathrm{C}_{10} \mathrm{H}_{12} \mathrm{~N}_{5} \mathrm{O}_{6} \mathrm{P}_{1}\right), \mathrm{C}\left(\mathrm{C}_{9} \mathrm{H}_{12} \mathrm{~N}_{3} \mathrm{O}_{7} \mathrm{P}_{1}\right), \mathrm{G}$ $\left(\mathrm{C}_{10} \mathrm{H}_{12} \mathrm{~N}_{5} \mathrm{O}_{7} \mathrm{P}_{1}\right)$, and $\mathrm{U}\left(\mathrm{C}_{9} \mathrm{H}_{11} \mathrm{~N}_{2} \mathrm{O}_{8} \mathrm{P}_{1}\right)$ residues. For calculation of ion abundance, counts for all peaks within an isotopic cluster were added, and the sum divided by the ion's charge to account for the fact that detector response scales linearly with charge in FT-ICR MS.

\section{Results and Discussion}

Figure 1a shows a mass spectrum of 34 nt RNA (10.9 $\mathrm{kDa}$ ) electrosprayed from a 1:1 methanol/water mixture at $\mathrm{pH} 9.5$, with molecular ion charge states ranging from 11- to $21-$. CAD of the $(\mathrm{M}-15 \mathrm{H})^{15-}$ ions with a laboratory frame collision energy of $105 \mathrm{eV}$ gave the spectrum shown in Figure 1b. Major CAD products are from base loss and the $a / w$ and $c / y$ backbone dissociations channels (Scheme 1). Fragment ions from the $\boldsymbol{b} / \boldsymbol{x}$ and $d / z$ channels were not observed, consistent with the

(a)
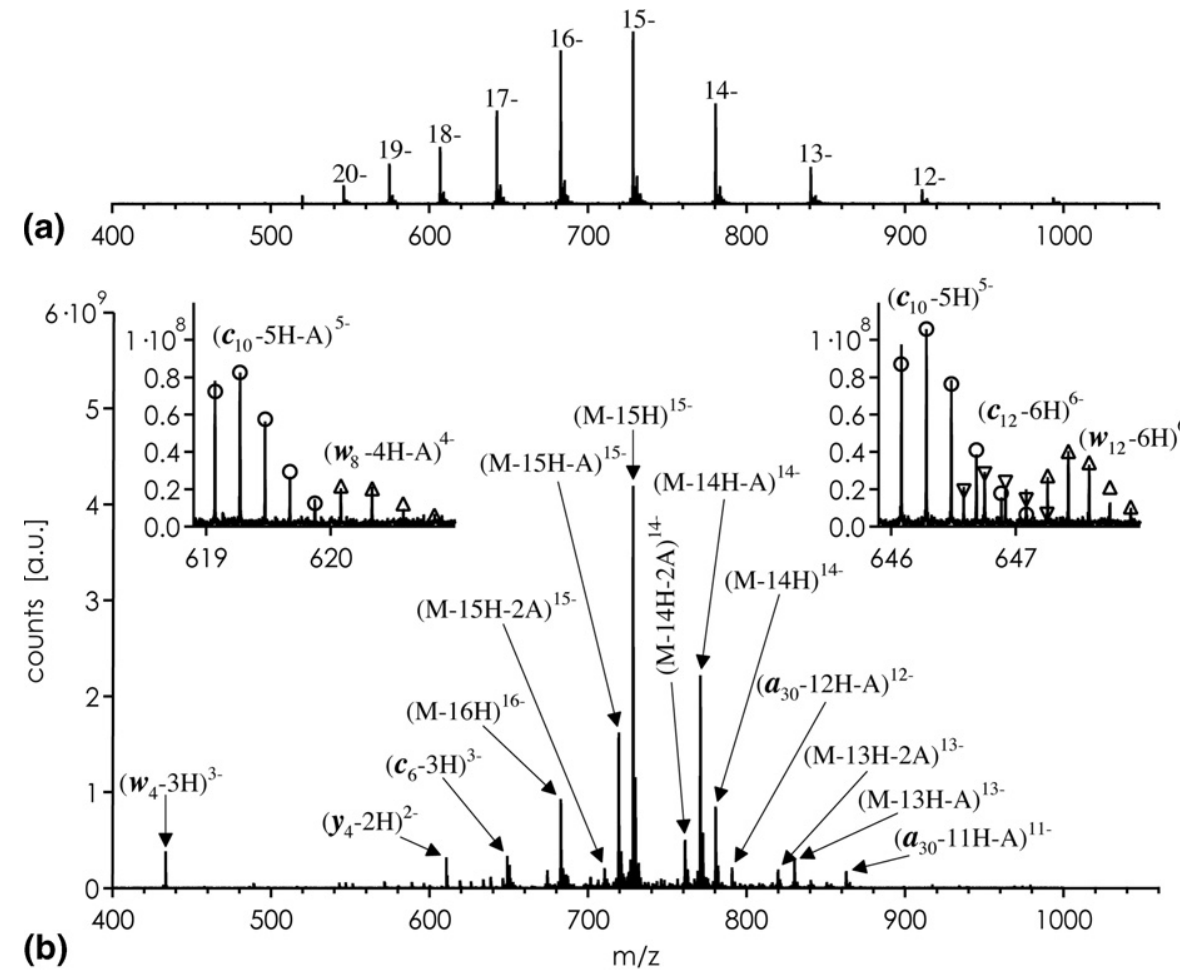

(c)

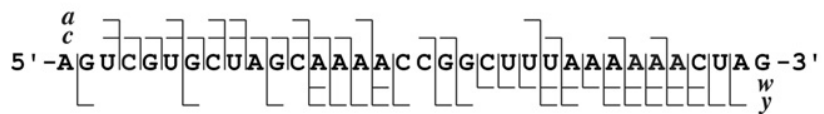

Figure 1. (a) ESI-MS spectrum of 34 nt RNA (variant $\mathrm{C}, 1 \mu \mathrm{M}$ in $\mathrm{H}_{2} \mathrm{O} / \mathrm{MeOH} 1: 1,1 \%$ vol. $\mathrm{Et}_{3} \mathrm{~N}$, pH 9.5); (b) CAD spectrum of $(\mathrm{M}-15 \mathrm{H})^{15-}$ ions (laboratory-frame collision energy $105 \mathrm{eV}$, collision gas flow $0.45 \mathrm{~L} / \mathrm{s}$ ), insets show characteristic fragment ions from RNA backbone cleavage, A stands for adenine; (c) fragment ion map illustrating sequence coverage. 
trend of decreasing $\boldsymbol{b}, \boldsymbol{x}, \boldsymbol{d}$, and $\boldsymbol{z}$ ion abundance with increasing oligonucleotide length discussed in the introduction. Sequence information from the spectrum in Figure $1 \mathrm{~b}$ is nearly complete, showing terminal fragment ions from backbone cleavage at 30 out of 33 possible sites (Figure 1c). However, substantial base loss from backbone fragment ions $(a: 72 \%, w$ : $13 \%, c$ : $17 \%, y: 7 \%$ ) seriously complicates spectral interpretation. As yet another limitation for de novo sequencing, only 10 out of 32 possible complementary $c / y$ fragment pairs [19] (whose mass values add up to the molecular mass) were found, along with 3 out of 33 possible $a / w$ pairs (Figure 1c). This relatively small yield of complementary pairs is the result of secondary backbone dissociation, which mainly reduces the number of higher mass primary fragment ions (Figure S1, which can be found in the electronic version of this article).

\section{Base Loss}

Out of the base losses from terminal fragments in Figure $1 b, 86 \%$ were loss of adenine, consistent with the base in the $5^{\prime}$ position being the most labile [12], and the RNA containing a relatively high proportion of adenine bases $(38 \%)$. The percentage of adenine base loss from molecular and selected $c$-type fragment ions in CAD of (M $15 \mathrm{H})^{15-}$ precursors (Figure S2) decreases with increasing collision gas flow rate, and increases with increasing collision energy. Increasing the collision gas flow rate from 0.1 to $0.75 \mathrm{~L} / \mathrm{s}$ at $105 \mathrm{eV}$ collision energy and from 0.1 to $0.9 \mathrm{~L} / \mathrm{s}$ at $128 \mathrm{eV}$ reduces base loss from molecular ions by $\sim 50 \%$ and $\sim 47 \%$, respectively. Base loss from backbone fragment ions generally decreases with increasing fragment ion mass at both 105 and $128 \mathrm{eV}$, possibly because the higher mass fragments have larger collision cross sections that are more susceptible to collisional deactivation after primary backbone cleavage.

Ion transmission through the hexapole collision cell decreases with increasing collision gas flow rate (Figure 2a) as a result of scattering ion-neutral collisions in the interface region between quadrupole and collision cell (Scheme 2). However, by using a more attractive bias potential on the hexapole $(\Delta \mathrm{V} \sim 1.1 \mathrm{~V}$, corresponding to an increase in laboratory frame collision energy of $\sim 17 \mathrm{eV}$ ), ion transmission in CAD of $(\mathrm{M}-15 \mathrm{H})^{15-}$ ions $(m / z 728)$ at $0.45 \mathrm{~L} / \mathrm{s}$ is comparable to that at $0.1 \mathrm{~L} / \mathrm{s}$ (Figure 2a). The total fragment ion yield increases sigmoidally with increasing collision energy (Figure $2 \mathrm{~b}$ ), with the data at $0.1 \mathrm{~L} / \mathrm{s}$ and $0.45 \mathrm{~L} / \mathrm{s}$ offset by $\sim 17$ $\mathrm{eV}$ as well. Similar results are obtained for CAD of $(\mathrm{M}-$ $12 \mathrm{H})^{12-}$ ions $(\mathrm{m} / \mathrm{z} 911)$, but with energy offsets of $\sim 10$ $\mathrm{eV}$ and $\sim 35 \mathrm{eV}$ for total fragment ion yield and ion transmission, respectively (Figure S3). Does this mean that spectra obtained at different gas flow rates, but showing the same extent of molecular ion dissociation, are just the same?

Figure 3 shows the extent of base loss from molecular and $c_{13}$ ions versus collision energy in CAD of $(\mathrm{M}-$
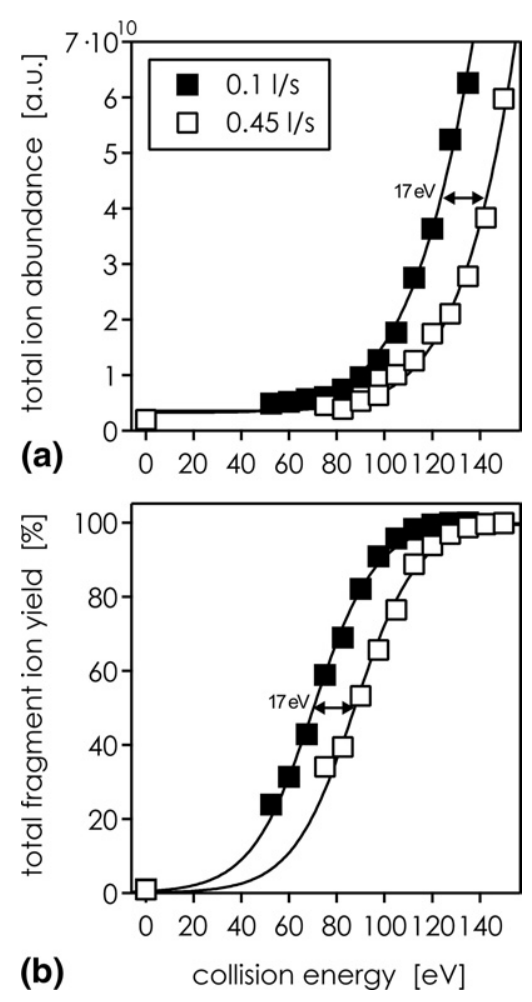

Figure 2. For 34 nt RNA (variant $\mathrm{C}, 1 \mu \mathrm{M}$ in $\mathrm{H}_{2} \mathrm{O} / \mathrm{MeOH} 1: 1,1 \%$ vol. $\mathrm{Et}_{3} \mathrm{~N}, \mathrm{pH}$ 9.5), (a) total ion abundance and (b) total fragment ion yield versus laboratory frame collision energy in CAD of (M $15 \mathrm{H})^{15-}$ for collision gas flow rates 0.1 and $0.45 \mathrm{~L} / \mathrm{s}$. Lines are meant to guide the eye.

$15 \mathrm{H})^{15-}$ and $(\mathrm{M}-12 \mathrm{H})^{12-}$ ions, with the data at $0.1 \mathrm{~L} / \mathrm{s}$ plotted against the bottom axes, and the data at $0.45 \mathrm{~L} / \mathrm{s}$ plotted against the top axes. The top and bottom axes are shifted against each other by 17 and $10 \mathrm{eV}$ for the $(\mathrm{M}-15 \mathrm{H})^{15-}$ and $(\mathrm{M}-12 \mathrm{H})^{12-}$ data, respectively. This presentation accounts for the above difference in laboratory frame collision energy required to give the same extent of molecular ion dissociation at collision gas flow rates 0.1 and $0.45 \mathrm{~L} / \mathrm{s}$. For CAD of $(\mathrm{M}-15 \mathrm{H})^{15-}$ (Figure $3 a)$ as well as $(\mathrm{M}-12 \mathrm{H})^{12-}$ (Figure $\left.3 \mathrm{~b}\right)$ ions, base loss increases with increasing collision energy. However, base loss at $0.1 \mathrm{~L} / \mathrm{s}$ collision gas flow rate is generally higher than at $0.45 \mathrm{~L} / \mathrm{s}$, most notably at higher collision energies. We reason that the steeper pressure gradient at higher gas flow rate allows for energetic collisions of precursor ions upon entering the collision cell volume (resulting in primary backbone cleavage), and at the same time makes possible more efficient collisional deactivation of primary fragment ions inside the collision cell (resulting in reduced base loss). Moreover, base loss in CAD of $(\mathrm{M}-15 \mathrm{H})^{15-}$ ions is much more pronounced than in CAD of $(\mathrm{M}-12 \mathrm{H})^{12-}$ ions at both collision gas flow rates, 0.1 and $0.45 \mathrm{~L} / \mathrm{s}$ (Figure 3 ). The collision cross sections of nucleic acids generally increase with increasing net charge [20, 21], so that collisional deactivation of $(\mathrm{M}-15 \mathrm{H})^{15-}$ and its primary fragment ions should be more efficient than for $(\mathrm{M}-12 \mathrm{H})^{12-}$ at any given gas flow rate. However, the contribution of 

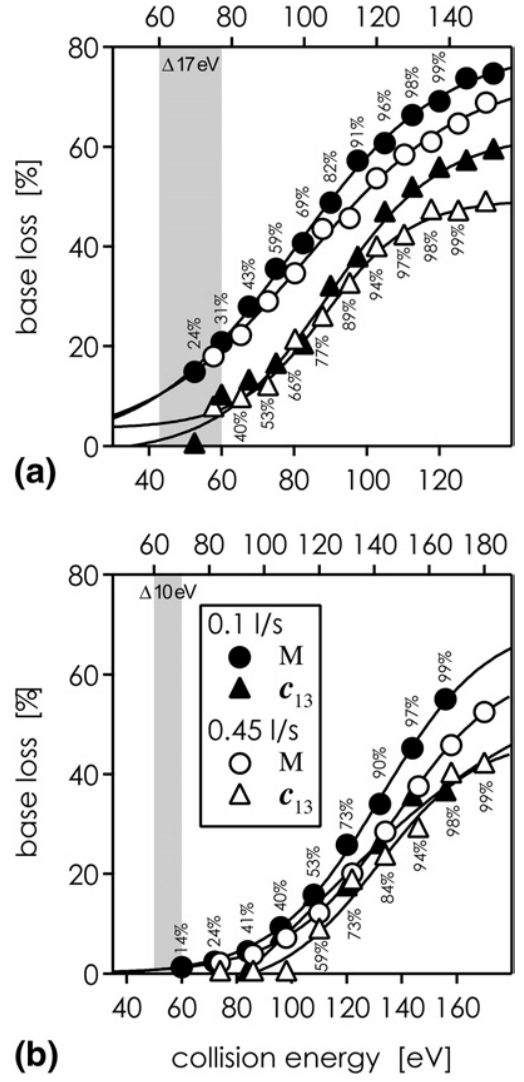

Figure 3. For 34 nt RNA (variant $\mathrm{C}$ ), relative loss of adenine from molecular and selected fragment ions in CAD of (a) (M $15 \mathrm{H})^{15-}$ from ESI of a $1 \mu \mathrm{M}$ solution in $\mathrm{H}_{2} \mathrm{O} / \mathrm{MeOH} 1: 1(1 \%$ vol. $\mathrm{Et}_{3} \mathrm{~N}, \mathrm{pH}$ 9.5) and (b) $(\mathrm{M}-12 \mathrm{H})^{12-}$ ions from ESI of a $1 \mu \mathrm{M}$ solution in $\mathrm{H}_{2} \mathrm{O} / \mathrm{MeOH}$ 7:3 (1\% vol. $\mathrm{Et}_{3} \mathrm{~N}$, pH 9.5) versus laboratory frame collision energy. Data for collision gas flow rates 0.1 and $0.45 \mathrm{~L} / \mathrm{s}$ are plotted versus the bottom and top axes, respectively, which are offset by $17 \mathrm{eV}$ in (a) and $10 \mathrm{eV}$ in (b). Percent values next to markers indicate extent of molecular ion dissociation. Lines are meant to guide the eye.

Coulombic to ion internal energy is not affected by ion-neutral collisions unless they cause changes in intramolecular charge distribution or three-dimensional structure of the ions. For the $(\mathrm{M}-15 \mathrm{H})^{15-}$ ions the proportion of Coulombic energy must be substantial, with a decrease of precursor ion charge from 15- to 12 - reducing base loss from molecular and $c_{13}$ fragment ions by $\sim 25 \%$ at both collision gas flow rates. The difference between the 0.1 and $0.45 \mathrm{~L} / \mathrm{s}$ data is least pronounced for $c_{13}$ from CAD of $(\mathrm{M}-12 \mathrm{H})^{12-}$ (Figure $3 \mathrm{~b})$. The average net charge of $c_{13}$ from CAD of (M $15 \mathrm{H})^{15-}$ and $(\mathrm{M}-12 \mathrm{H})^{12-}$ is -5.6 and -4.8 , respectively. Because of reduced Coulombic repulsion, the $c_{13}$ ions from CAD of $(\mathrm{M}-12 \mathrm{H})^{12-}$ should have the smallest collision cross section among the four ion species considered in Figure 3. Presumably, the rates of collisional cooling at 0.1 and $0.45 \mathrm{~L} / \mathrm{s}$ cannot effectively compete with the rate of base loss from the more compact $c_{13}$ ions. Further reduction of base loss would then require significantly higher collision gas flow rates, but with detrimental effect on transmission of molecular ions and their CAD products through the collision cell.

\section{Secondary Fragmentation}

Figure 4 shows abundances of selected ions from backbone cleavage and base loss versus collision energy. The general features of the data are the same for both charge states, 15- and 12-, and collision gas flow rates, 0.1 and $0.45 \mathrm{~L} / \mathrm{s}$, studied in such detail: with increasing collision energy, the abundances of $c_{10}, c_{13}, c_{18}$, and $a_{13}$-A ions increase to a maximum value, and then decrease as a result of secondary fragmentation. Products from secondary backbone cleavage include internal fragments (e.g., $\mathrm{AAA}_{\text {int }}$ ) as well as smaller terminal fragments (e.g., $c_{4}$ ), whose abundances increase at the expense of higher-mass primary fragment ions at higher collision energies (Figure 4).

A major difference between the data at 0.1 and 0.45 $\mathrm{L} / \mathrm{s}$ is that for the latter, the collision energy ranges yielding $>50$ and $<99 \%$ molecular ion dissociation (areas shaded in gray) are generally broader, especially for CAD of $(\mathrm{M}-12 \mathrm{H})^{12-}$ ions. The smaller effect of collision gas flow rate on backbone fragmentation in CAD of $(\mathrm{M}-15 \mathrm{H})^{15-}$ (Figure $4 \mathrm{a}$ and $\mathrm{b}$ ) is consistent with Coulombic energy making up a significant contribution to internal energy in both precursor and product ions, as collisional cooling affects only non-Coulombic, i.e., vibrational energy. For the $(\mathrm{M}-12 \mathrm{H})^{12-}$ ions, on the other hand, collisional deactivation is more effective because the contribution of Coulombic to internal energy is smaller. This reasoning is also supported by the observation that cooling is generally more effective in reducing base loss at higher collision energies where the proportion of vibrational energy is higher (Figure 3). The relative abundance of internal fragments from secondary backbone fragmentation, e.g., $\mathrm{AAA}_{\text {int }}$, is generally higher at 0.1 than $0.45 \mathrm{~L} / \mathrm{s}$ for comparable extents of molecular ion dissociation (Figure 4). For example, at $73 \%$ dissociation of $(\mathrm{M}-12 \mathrm{H})^{12-}$, the $\left[\mathrm{AAA}_{\mathrm{int}}\right] /\left[c_{13}\right]$ ratio is 0.41 and 0.30 at collision gas flow rates 0.1 and $0.45 \mathrm{~L} / \mathrm{s}$, respectively. In line with the above rationale, the effect is more pronounced in CAD of $(\mathrm{M}-12 \mathrm{H})^{12-}$ than for $(\mathrm{M}-15 \mathrm{H})^{15-}$ ions, and also at higher collision energy (Figure S4).

\section{Backbone Dissociation Channels}

The major difference between CAD of $(\mathrm{M}-15 \mathrm{H})^{15-}$ and $(\mathrm{M}-12 \mathrm{H})^{12-}$ ions is that for the latter, $c$ ion abundance is generally higher, consistent with reduced base loss in CAD of $(\mathrm{M}-12 \mathrm{H})^{12-}$ (Figure $\left.3 \mathrm{~b}\right)$, and preference for the $c / y$ over the $a / w$ channel at lower precursor ion charge. Moreover, in CAD of (M $15 \mathrm{H})^{15-}$ ions, the onsets for $a_{13}$-A ion formation are at lower energy than the onsets for formation of the internal fragment $\mathrm{AAA}_{\text {int }}$ (Figure $4 \mathrm{a}$ and $\mathrm{b}$ ), but this order is reversed in CAD of $(\mathrm{M}-12 \mathrm{H})^{12-}$ ions (Figure $4 \mathrm{c}$ and d). Removal of only $20 \%$ of the molecular ion's net charge (from 15- to 12-) changes the branching ratio of backbone cleavage products in favor and disfavor of the $c / y$ and $a / w$ fragmentation channels, respectively. 

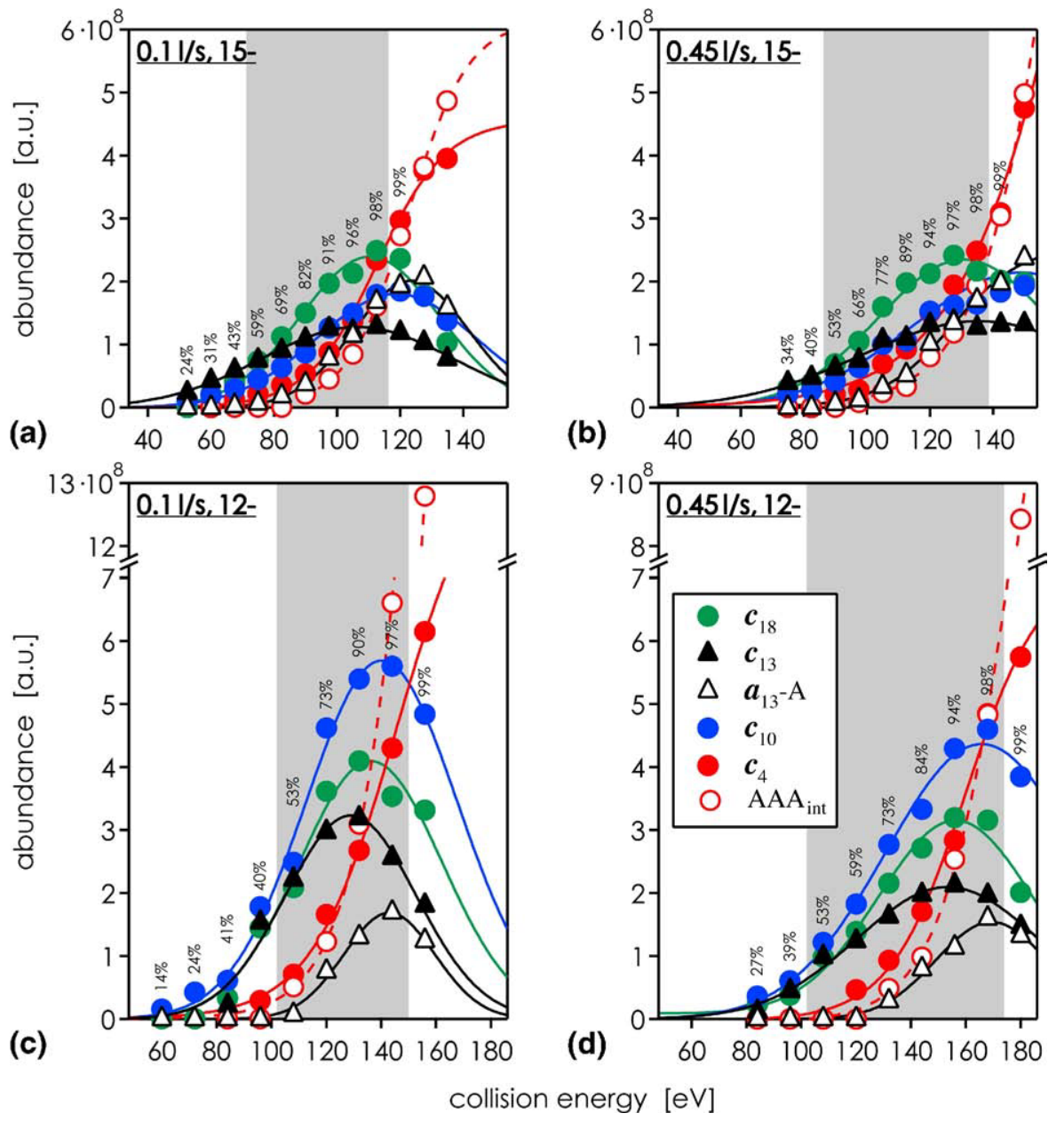

Figure 4. For 34 nt RNA (variant C), abundance of selected fragment ions in CAD of (a), (b) (M $15 \mathrm{H})^{15-}$ from ESI of a $1 \mu \mathrm{M}$ solution in $\mathrm{H}_{2} \mathrm{O} / \mathrm{MeOH} 1: 1\left(1 \%\right.$ vol. $\left.\mathrm{Et}_{3} \mathrm{~N}, \mathrm{pH} 9.5\right)$ and (c), (d) $(\mathrm{M}-$ $12 \mathrm{H})^{12-}$ ions from ESI of a $1 \mu \mathrm{M}$ solution in $\mathrm{H}_{2} \mathrm{O} / \mathrm{MeOH} 7: 3\left(1 \%\right.$ vol. $\left.\mathrm{Et}_{3} \mathrm{~N}, \mathrm{pH} 9.5\right)$ versus laboratory frame collision energy for collision gas flow rates (a), (c) $0.1 \mathrm{~L} / \mathrm{s}$ and (b), (d) $0.45 \mathrm{~L} / \mathrm{s}$. Collision energy ranges required for $>50 \%$ to $<99 \%$ molecular ion dissociation are highlighted as gray areas. Percent values next to markers indicate extent of molecular ion dissociation. Lines are meant to guide the eye.

The highest abundance of primary $c$ ions, along with minimal secondary fragmentation, is obtained with $\sim 50 \%$ to $\sim 80 \%$ molecular ion dissociation (Figure 4). This is true for both charge states and collision gas flow rates studied here, and agrees well with our general experience that the best CAD spectra of multiply deprotonated RNA are obtained at collision energies that reduce the precursor ion abundance to $\sim 30 \%-40 \%$.

With $59 \%$ precursor ion depletion in CAD of $(\mathrm{M}-$ $12 \mathrm{H})^{12-}$ ions of $34 \mathrm{nt}$ RNA at collision gas flow rate 0.45 $\mathrm{L} / \mathrm{s}$, we obtain a spectrum that is dominated by fragment ions from the $c / y$ backbone dissociation channel ( $98 \%$ of all assigned backbone fragment ions), and completely devoid of $\boldsymbol{a}$ and ( $\boldsymbol{a}$-B) ions; $\boldsymbol{w}$ ions make up $2 \%$ of all assigned backbone fragment ions (Figure S5a). Sequence coverage is nearly complete (Figure S5b), showing terminal fragment ions from cleavage at 30 out of 33 possible sites. At the same time, overall base loss from molecular and assigned backbone fragment ions is only $12 \%$ and $4 \%$, respectively, significantly less than that for CAD of $(\mathrm{M}-15 \mathrm{H})^{15-}$ ions (Figure 1). The Figure S5 data also gave a higher number of complementary $c / y$ ion pairs, 23 out of 32 possible. Most of the missing complementary ions are higher mass $c$ and $y$ fragments (Figure S5b), which appear to be more prone to secondary backbone dissociation than fragment ions of lower mass. From the numbers of complementary ion pairs in CAD of $(\mathrm{M}-15 \mathrm{H})^{15-}$ (Figure 1c) and $(\mathrm{M}-$ $12 \mathrm{H})^{12-}$ (Figure S5b), 10 and 23, respectively, it is evident that precursor ion net charge is in large part responsible for decomposition of larger primary fragment ions. Two charge-related factors could contribute to secondary backbone dissociation: first, Coulombic repulsion generally decreases (primary) ion stability; second, if backbone cleavage involves negative charge, as suggested by Schürch and coworkers [13], chances for secondary backbone dissociation 
(a)
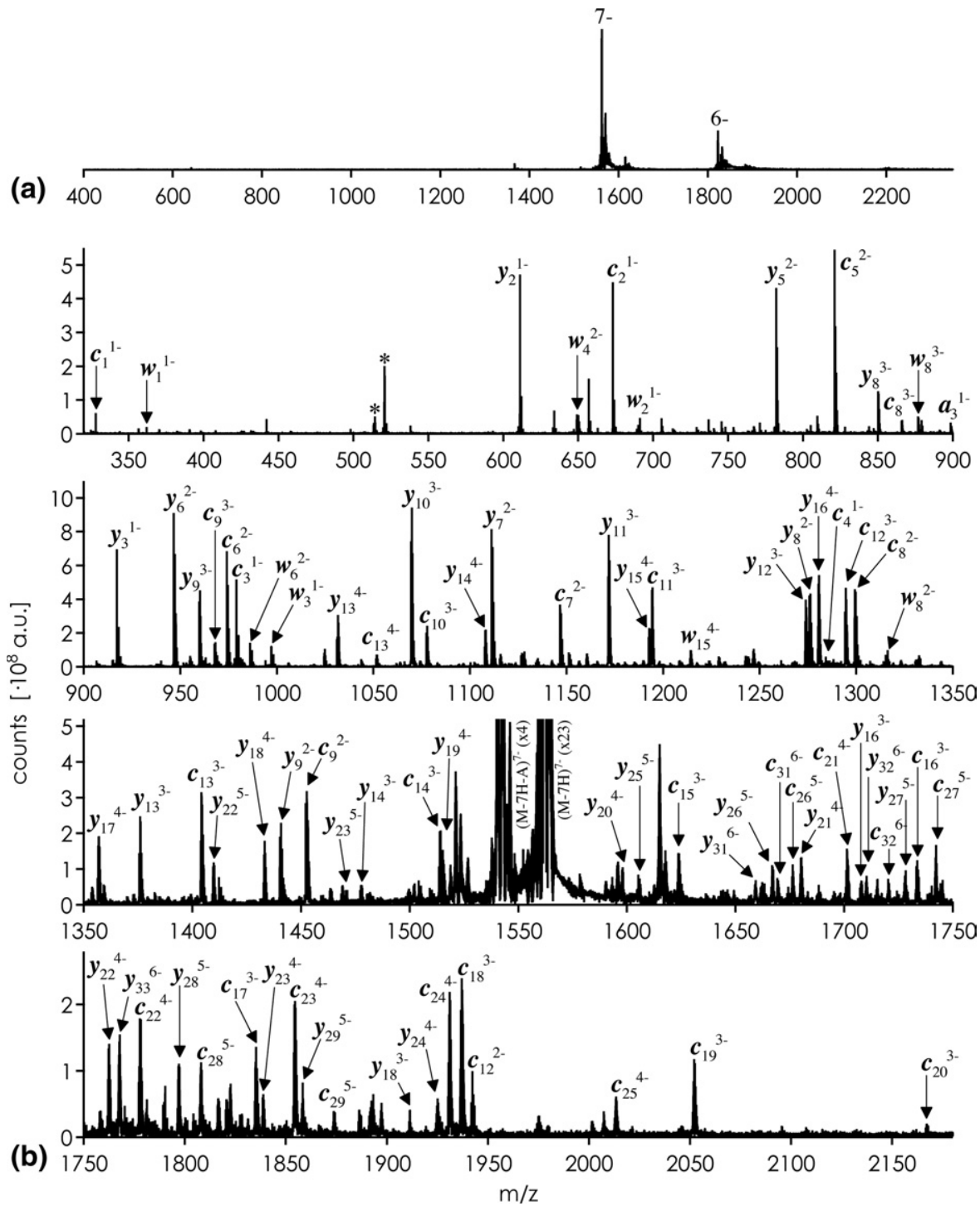

Figure 5. (a) ESI-MS spectrum of $34 \mathrm{nt} \mathrm{RNA}$ (variant $\mathrm{B}, 1 \mu \mathrm{M}$ in $\mathrm{H}_{2} \mathrm{O} / \mathrm{MeOH} 1: 1, \sim 0.05 \%$ vol. $\mathrm{HOAc}$, $\mathrm{pH} 2.5)$; (b) CAD spectrum of $(\mathrm{M}-7 \mathrm{H})^{7-}$ ions (laboratory-frame collision energy $126 \mathrm{eV}$, collision gas flow $0.45 \mathrm{~L} / \mathrm{s})$. Asterisks indicate harmonic peaks of $(\mathrm{M}-7 \mathrm{H})^{7-}$ and $(\mathrm{M}-7 \mathrm{H}-\mathrm{A})^{7-}$.

should decrease with decreasing charge. Following this logic, further reduction of precursor ion charge should increase the number of higher mass primary backbone fragments and complementary $c / y$ ion pairs. However, ESI of 34 nt RNA in $\mathrm{H}_{2} \mathrm{O} / \mathrm{MeOH}$ mixtures with the $\mathrm{pH}$ adjusted to 9.5 by addition of triethylamine generally did not produce significant amounts of molecular ions with charge states $<-12$ (Figure 1a).

\section{CAD of Precursor Ions of Reduced Charge}

Charge state reduction of small multiply deprotonated DNA by addition of acetic acid to the ESI solution was reported by Smith and coworkers [22]. We find that acetic acid is equally effective in reducing ion charge during ESI of our $34 \mathrm{nt}$ RNA; adjusting the $\mathrm{pH}$ of the ESI solution to 2.5 by addition of $\sim 0.05 \%$ HOAc gave the spectrum shown in Figure $5 \mathrm{a}$, CAD of the $(\mathrm{M}-7 \mathrm{H})^{7-}$ ions, which carry less than half of the charge than the $(\mathrm{M}-15 \mathrm{H})^{15-}$ ions (Figure $1 b)$, gave the spectrum shown in Figure $5 b$, which is dominated by abundant $c$ and $y$ ions.

The CAD spectrum in Figure $5 \mathrm{~b}$ shows largely nonselective backbone cleavage with respect to nucleobase composition (Figure 6a), and provides complete sequence coverage (Figure 6b). Backbone cleavage via primarily the $c / y$ channel ( $91 \%$ of all terminal backbone fragments) produced 30 out of 32 possible complementary $c / y$ ion pairs whose mass values add up to the molecular ion mass (Figure 6b). Reduced secondary fragmentation compared with CAD of $(\mathrm{M}-15 \mathrm{H})^{15-}$ (Figure $1 \mathrm{c})$ and $(\mathrm{M}-12 \mathrm{H})^{12-}$ (Figure $\left.\mathrm{S} 5 \mathrm{~b}\right)$ is evident from the increased number of higher mass $c$ and $y$ fragment ions (Figure 6b). 


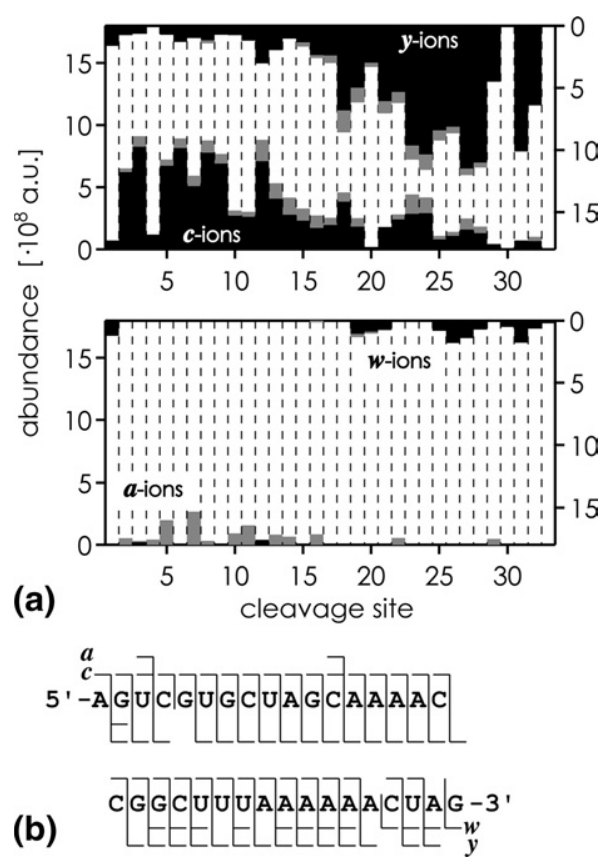

Figure 6. For 34 nt RNA (variant $\mathrm{B}, 1 \mu \mathrm{M}$ in $\mathrm{H}_{2} \mathrm{O} / \mathrm{MeOH}$ 1:1 $\sim 0.05 \%$ vol. HOAc, $\mathrm{pH} 2.5$ ), (a) abundance of terminal backbone fragment ions in CAD of $(\mathrm{M}-7 \mathrm{H})^{7-}$ ions (laboratory frame collision energy: $126 \mathrm{eV}$, collision gas flow rate: $0.45 \mathrm{~L} / \mathrm{s}$ ) versus cleavage site, with $c, y, a$, and $w$ ions shown as black, and base losses as gray bars; (b) fragment ion map illustrating sequence coverage.

\section{Conclusions}

Our concept of collisionally cooling the fragment ions from primary backbone cleavage in CAD of lower charge precursor ions now enables de novo sequencing of $34 \mathrm{nt}$ RNA by top-down mass spectrometry. Experimental conditions include use of high collision gas flow rates as well as selection of precursor ions of relatively low negative net charge (about $-0.2 / \mathrm{nt}$ ). The key idea is to minimize internal energy of primary fragment ions by collisional cooling (minimizing vibrational energy) and reduced charge (minimizing Coulombic energy). Moreover, if the mechanism for backbone cleavage involves negative charge, chances for secondary backbone dissociation decrease with decreasing precursor ion charge. Coincidentally, lower precursor ion charge states changes the branching ratio between $a / w$ and $c / y$ dissociation channels in favor of formation of complementary $c$ and $y$ ions (>90\%); $a$ ions have a much higher tendency for base loss and the resulting $(a-B)$ ions are less useful for de novo sequencing. The above experimental conditions significantly reduce interfering base loss and secondary fragmentation, providing complete sequence coverage and 30 out of 32 possible complementary $c / y$ ion pairs for $34 \mathrm{nt}$ RNA. Reducing the charge of precursor RNA ions here was achieved by acidification of the ESI spray solution. We are currently studying other ESI additives for charge reduction, and extending our methodology to larger RNA.

\section{Acknowledgments}

The authors acknowledge discussion with Ronald Micura and Dagmar Graber, and financial support from the Austrian Science Fund (FWF projects Y372 to K.B. and P17864 to R.M.).

\section{Appendix A Supplementary Material}

Supplementary material associated with this article may be found in the online version at doi:10.1016/ j.jasms.2009.10.010.

\section{References}

1. Limbach, P. A.; Crain, P. F.; McCloskey, J. A. Characterization of Oligonucleotides and Nucleic Acids by Mass Spectrometry. Curr. Opin. Biotechnol. 1995, 6, 96-102.

2. Oberacher, H.; Pitterl, F. On the Use of ESI-QqTOF-MS/MS for the Comparative Sequencing of Nucleic Acids. Biopolymers 2009, 91, 401409 .

3. Huang, T.; Liu, J.; Liang, X.; Hodges, B. D. M.; McLuckey, S. A. Collision-Induced Dissociation of Intact Duplex and Single-Stranded siRNA Anions. Anal. Chem. 2008, 80, 8501-8508.

4. Bahr, U.; Aygün, H.; Karas, M. Sequencing of Single and Double Stranded RNA Oligonucleotides by Acid Hydrolysis and MALDI Mass Spectrometry. Anal. Chem. 2009, 81, 3173-3179.

5. Meng, Z.; Limbach, P. A. RNase Mapping of Intact Nucleic Acids by Electrospray Ionization Fourier Transform Ion Cyclotron Resonance Mass Spectrometry (ESI-FTICR-MS) and ${ }^{18} \mathrm{O}$ Labeling. Int. J. Mass Spectrom. 2004, 234, 37-44.

6. Farand, J.; Gosselin, F. De Novo Sequence Determination of Modified Oligonucleotides. Anal. Chem. 2009, 81, 3723-3730.

7. Aebersold, R.; Mann, M. Mass Spectrometry-Based Proteomics. Nature 2003, 422, 198-207.

8. Little, D. P.; Aaserud, D. J.; Valaskovic, G. A.; McLafferty, F. W. Sequence Information from 42-108-mer DNAs (Complete for a 50-mer) by Tandem Mass Spectrometry. I. Am. Chem. Soc. 1996, 118, 9352-9359.

9. Han, X.; Jin, M.; Breuker, K.; McLafferty, F. W. Extending Top-Down Mass Spectrometry to Proteins with Masses Greater Than 200 Kilodaltons. Science 2006, 314, 109-112.

10. Chait, B. T. Mass Spectrometry: Bottom-Up or Top-Down? Science 2006, 314, 65-66.

11. McLuckey, S. A.; Van Berkel, G. J.; Glish, G. L. Tandem Mass Spectrometry of Small, Multiply Charged Oligonucleotides. J. Am. Soc. Mass Spectrom. 1992, 3, 60-70.

12. Huang, T.; Kharlamova, A.; Liu, J.; McLuckey, S. A. Ion Trap CollisionInduced Dissociation of Multiply Deprotonated RNA: $c / y$-Ions versus (a-B)/w-Ions. J. Am. Soc. Mass Spectrom. 2008, 19, 1832-1840.

13. Tromp, J. M.; Schürch, S. Gas-Phase Dissociation of Oligoribonucleotides and Their Analogs Studied by Electrospray Ionization Tandem Mass Spectrometry. J. Am. Soc. Mass Spectrom. 2005, 16, 1262-1268.

14. Schürch, S.; Bernal-Mendez, E.; Leumann, C. J. Electrospray Tandem Mass Spectrometry of Mixed-Sequence RNA/DNA Oligonucleotides. J. Am. Soc. Mass Spectrom. 2002, 13, 936-945.

15. Tromp, J. M.; Schürch, S. Electrospray Ionization Tandem Mass Spectrometry of Biphenyl-Modified Oligo(Deoxy)ribonucleotides. Rapid Commun. Mass Spectrom. 2006, 20, 2348-2354.

16. Micura, R. Small Interfering RNAs and Their Chemical Synthesis. Angew. Chem. Int. Ed. 2002, 41, 2265-2269.

17. Rieder, U.; Lang, K.; Kreutz, C.; Polacek, N.; Micura, R. Evidence for Pseudoknot Formation of Class 1 preQ ${ }_{1}$ Riboswitch Aptamers. Chem. BioChem. 2009, 10, 1141-1144.

18. Gabelica, V.; de Pauw, E. Internal Energy and Fragmentation of Ions Produced in Electrospray Sources. Mass Spectrom. Rev. 2005, 24, 566587.

19. The Complement of $c_{33}, y_{1}$, Lacks a Phosphate as Deprotonation Site and cannot be Detected.

20. Hoaglund, C. S.; Liu, Y.; Ellington, A. D.; Pagel, M.; Clemmer, D. E Gas-Phase DNA: Oligothymidine Ion Conformers. J. Am. Chem. Soc. 1997, 119, 9051-9052.

21. Moradian, A.; Scalf, M.; Westphall, M. S.; Smith, L. M.; Douglas, D. J. Collision Cross Sections of Gas Phase DNA Ions. Int. J. Mass Spectrom. 2002, 219, 161-170.

22. Cheng, X.; Gale, D. C.; Udseth, H. R.; Smith, R. D. Charge State Reduction of Oligonucleotide Negative Ions from Electrospray Ionization. Anal. Chem. 1995, 67, 586-593. 